\title{
PEDAGOGIA E O PROFESSOR POLIVALENTE: UM CAMPO COMPLEXO DE ATUAÇÃO PROFISSIONAL
}

\author{
PEDAGOGÍA Y EL PROFESOR POLIVALENTE: UN CAMPO CONPLEJO DE \\ ACTUACIÓN PROFESIONAL
}

PEDAGOGY AND THE MULTIPURPOSE TEACHER: A COMPLEX PROFESSIONAL FIELD

Eder VACILOTTO ${ }^{1}$

Ivan FORTUNATO ${ }^{2}$

RESUMO: Este artigo apresenta um panorama do exercício profissional do Professor Polivalente, egresso da Pedagogia, proporcionando um diálogo entre relatos reflexivos da educação básica e elementos de sua constituição, com o objetivo de levantar possibilidades para melhoria de sua formação. Para trilhar este caminho, apresentamos esse profissional sobre o conceito de escolarização e sua influência na constituição da sua identidade, com aporte teórico diverso pela ótica do espaço escolar. Sobre um caminho de incertezas, a trajetória do Professor Polivalente é construída. Identificam-se possibilidades e caminhos formativos que entrelaçam a formação inicial com a formação continuada em exercício, que no dia a dia da escola, possibilitam avanços nas condições pedagógicas. A pesquisa reconhece como a formação inicial pode se apresentar como incompleta ou incerta, mas, seus conceitos e predicados emergem nas tarefas e nos desafios diários do exercício docente, exigindo revisitálos, fortalecê-los e ampliá-los.

PALAVRAS-CHAVE: Pedagogia. Professor polivalente. Escolarização.

RESUMEN: Este artículo aporta un panorama del ejercicio profesional del Profesor Polivalente, egreso de la pedagogía, proporcionando un diálogo entre los informes reflexivos de la educación básica y los elementos de su constitución, con el fin de generar posibilidades para mejorar su educación. Para seguir este camino, presentamos a este profesional sobre el concepto de escolarización y su influencia en la constitución de su Identidad, con diferentes soportes teóricos desde la perspectiva del espacio escolar. En un camino de incertidumbre, se construye la trayectoria del Profesor Polivalente. Se identifican posibilidades de formación y caminos que entrelazan la formación inicial con la formación continua en ejercicio, que en el día a día de la escuela, permiten avances en las condiciones pedagógicas. La investigación reconoce cómo la formación inicial puede presentarse como incompleta o incierta, pero sus conceptos y predicados emergen en las tareas y desafíos cotidianos de la docencia, requiriendo revisarlos, fortalecerlos y ampliarlos.

\section{PALABRAS CLAVE: Pedagogía. Profesor polivalente. Escolarización.}

\footnotetext{
${ }^{1}$ Secretaria Municipal de Educação (SME), Itu - SP - Brasil. Coordenador Pedagógico da Prefeitura. Mestrado em Educação (UFSCAR). ORCID: https://orcid.org/0000-0003-1215-3381. E-mail: ivanfrt@yahoo.com.br

2 Instituto Federal de São Paulo (IFSP), Itapetininga - SP - Brasil. Coordenadoria de Formação Pedagógica. Doutorado em Desenvolvimento Humano e Tecnologias (UNESP). ORCID: https://orcid.org/0000-0002-18707528. E-mail: ivanfrt@yahoo.com.br
} 
ABSTRACT: This paper presents an overview of the Multipurpose Teacher professional exercise with a Pedagogy degree, providing a dialogue among reflective reports of basic education and elements of its constitution, with the main objective to raise possibilities for improving their formation. In order to tread this journey, we introduce this professional about the concept of schooling and its influence in the constitution of his/her Identity, with diverse theoretical support from the perspective of the school space. On a path of uncertainty, the journey of a Multipurpose teacher is developed. Training possibilities and paths are identified that intertwine the initial training with the continuing training in exercise, which in the dayto-day of the school, allow advances in the pedagogical conditions. The research recognizes that the initial formation can be listed as incomplete or uncertain, but their concepts and predicates emerge in the daily tasks and challenges of teaching, demanding to revisit, strengthen and expand them.

KEYWORDS: Pedagogy. Multipurpose teacher. Schooling.

\section{Introdução}

Este artigo apresenta um panorama do exercício profissional do Professor Polivalente, egresso da licenciatura em Pedagogia, proporcionando um diálogo entre relatos reflexivos da educação básica e elementos de sua constituição, com o objetivo de levantar possibilidades para melhoria de sua formação. Foi escrito a partir dos principais argumentos elucidados em uma dissertação de mestrado, defendida no Programa de Pós-Graduação em Educação, da Universidade Federal de São Carlos, campus Sorocaba (VACILOTTO, 2020). Como formados em Pedagogia e professores, o percurso tomado na escrita desse artigo é orgânico, pois parte do vivido para o diálogo reflexivo com a literatura. Está (des)organizado em várias seções, mimetizando as mais variadas situações do cotidiano escolar, sobre o qual não há controle das situações espontâneas, muitas imprevisíveis, que vão compondo o mosaico da experiência docente.

Vejamos. No primeiro horário do período da manhã, o sinal toca. Por todos os lados, estudantes buscando ocupando seus lugares - concreta e metaforicamente. Nos bastidores de um dia escolar, meia hora antes, temos a chegada dos gestores, coordenadores e professores, todos com atribuições bem diversas e complementares, para que aquele dia seja especial na vida do alunado. O que temos em comum entre esses três profissionais, além dos desafios diários emergentes do cotidiano escolar? O curso de Pedagogia, pois, em linhas gerais, para exercer qualquer uma dessas profissões é preciso ter cursado essa licenciatura. Ao concluir o curso de Pedagogia, o egresso pode se tornar efetivamente um Professor Polivalente, além de 
estar apto a exercer diversos cargos na educação. Isso pode ser lido nas Diretrizes Curriculares Nacionais da Pedagogia, conforme artigo a seguir:

Art. $4^{\circ}$. O curso de Licenciatura em Pedagogia destina-se à formação de professores para exercer funções de magistério na Educação Infantil e nos anos iniciais do Ensino Fundamental, nos cursos de Ensino Médio, na modalidade Normal, de Educação Profissional na área de serviços e apoio escolar e em outras áreas nas quais sejam previstos conhecimentos pedagógicos (BRASIL, 2006, p. 2).

Mas, ao optar pela docência, é preciso entender como se dá a rotina escolar, entender que a escola é espaço de múltiplas culturas, que para Candau (2008) é um espaço de produção cultural, onde há um complexo cruzamento de culturas. A partir dessa ideia da autora, a questão da cultura na escola já foi abordada em outro momento, reconhecendo que nosso olhar deve se voltar para identificar, compreender, aceitar e partilhar as diferenças do cotidiano (FORTUNATO, 2018).

É como Paulo Freire (1997) uma vez anotou: “[...] vou tomar como objeto de minha reflexão não só as relações que o contexto concreto e o teórico estabelecem entre si, mas também a maneira como, em cada um deles, nos comportamos" (p. 68). Assim, em diálogo com essas (e muitas outras) teorias, vamos partilhando relatos de experiências, tornando-os trilhas formativas para identificar elementos de constituição da identidade do Professor Polivalente.

Assumimos, desde já, os predicados tecidos por Contreras (2016, p. 15):

Nossa profissão educacional, como uma profissão do humano, pode ser uma fonte de experiência, se prestamos atenção ao que nos acontece e se elaboramos e expressamos de uma forma ligada à experiência, isto é, como narrativa. Mas, como um modo de indagação, o seu objetivo não acaba apenas no registro de narrativa, mas procura fazer visíveis e pensáveis questões educativas que, por meio de narrar-se nos desvendam. Porque em grande medida o conhecimento pedagógico que os educadores precisam é um saber que possa ser ligado à experiência, que possa partir da experiência, para voltar ao que vivemos com maior sensibilidade, consciência e abertura.

Os relatos de experiência traçam um caminho formativo, de construção autobiográfica, da constituição de se tornar Professor Polivalente. Trajetos concretos que se contrapõem as teorias e os conceitos. Ao tratar sobre relato de experiência como método de construção de conhecimento em educação, já foi indicado que o resultado buscado é o de conhecer a si mesmo, pela própria ótica, a se ver refletido nas mais distintas realidades que se pretende examinar (FORTUNATO, 2018). De certa forma, é o que almejamos fazer aqui.

Professor Polivalente e seus caminhos de formação 
O Professor Polivalente é o profissional formado pela Pedagogia que atua na docência da educação infantil e/ou nos anos iniciais do ensino fundamental, do primeiro ao quinto ano. Para Libâneo (2002, p. 64): "a Pedagogia é o campo científico, não um curso. O curso que lhe corresponde forma o investigador da educação e o profissional que realiza tarefas educativas, seja ele docente ou não diretamente docente". O curso é regido por diretrizes próprias, datadas de 2006 que, desde então, passam por mudanças significativas para adequar a formação do professor às perspectivas educacionais. O Professor Polivalente pode atuar em diferentes espaços, como se discute nas seções seguintes.

\section{A Educação Infantil}

O Professor Polivalente, no ambiente da Educação Infantil, tem papel importante no desenvolvimento da autonomia dos alunos. Um dos desafios ao trabalho com estudantes da educação infantil é o contexto de separação parcial com a família. Muitos alunos entram para a instituição com apenas seis meses de idade, criando uma rotina de autonomia e independência bastante precoce - às vezes para os pais, inclusive.

Aqui, a mediação de conflitos é primordial, tanto para a gestão como para os professores, pois vínculos estão sendo quebrados para que novas situações afetivas aconteçam. Eis um relato vivido alguns anos atrás, quando um de nós atuava como professor em uma creche.

\section{O primeiro dia de uma creche}

Ao assumir meu segundo concurso na cidade de Itu, tive a experiência de cumprir alguns dias em uma Creche, pois, naquele ano, não tinha ainda acumulado o período de férias integral.

A primeira semana foi intensa em fatos e situações, me ajudando a crescer rapidamente como Polivalente, principalmente por ajudar a entender que, apesar de concluída a graduação, ainda não tinha todas as habilidades para dar conta de tantas atribuições diversas.

Devido às escolas estarem em período de férias e somente as creches em pleno funcionamento, passei alguns dias cumprindo meu horário neste ambiente.

Observei que aquela semana era a primeira para muitos bebês, e os profissionais que ali atuavam não conheciam as crianças, nem os condutores que as transportavam até ali 
(muitos bebês são levados por vans de transporte escolar, pois os pais não conseguem adequar seus horários de trabalho com o da instituição).

Os alunos em fase de adaptação são estimulados a brincar, a rolar em espaços adequados e livres para novas experiências. Histórias são contadas, pequenas músicas cantadas, refeições e mais refeições são servidas. Esse seria um dia tranquilo, se não fosse pelo momento da saída, quando uma condutora, ao buscar a criança, não sabia qual era o bebê. Explico: muitos alunos são matriculados com seis meses de idade, não possuem a autonomia da linguagem oral e não atendem pelos seus nomes, visto que essa etapa só acontece posteriormente.

O nervosismo toma conta de todos os gestores, afinal é uma situação grave. Se você não sabe qual o aluno que busca, mas possui todas as autorizações para isso, como a escola deve proceder? Ligar para os pais e perguntar qual é seu filho, acredito que não seria o mais adequado. Foi quando uma Professora Polivalente, que estava ausente nesse momento por atender outras demandas, foi chamada e, ao ser perguntada sobre qual era o aluno, prontamente mostrou um crachá que havia feito, com o nome do aluno, características de suas roupas, nome dos pais e dos condutores. Confesso que até eu, que observava a cena, me senti aliviado, e na hora pensei: como a experiência de trabalho faz com que aprendamos situações da prática. Nos anos que cursei a Pedagogia, nunca me perguntei como seria a identificação de bebês ou como era realizado este horário de saída. Aliás, jamais pensei ter essa tarefa como atribuição do cargo.

Existem peculiaridades da rotina escolar que só se tornam conhecidas quando nelas estivermos inseridos. Esses detalhes de identificação, de como proceder com bebês, são características construídas com a prática. É possível que o estudante de Pedagogia, ao realizar o estágio supervisionado, tome conhecimento desses detalhes, ou dependendo do período no qual realizou sua tarefa, a familiaridade dos bebês com seus cuidadores já era estabelecida, não sendo necessário mais nenhum crachá. Logo o estudante também não saberia como lidar com tal situação.

O exemplo do relato nos traz a perspectiva de apresentar a escola em seu cotidiano. É certo que as instituições de ensino superior não dão conta de todas as especificidades, pois isso requer a prática do dia a dia, a troca entre os pares. O estágio supervisionado também é uma ferramenta fundamental nesses casos, pois, quando bem aplicado, resulta em conhecimento e novas experiências. Conforme vimos com Pimenta (1995), o estágio é (ou deveria ser) o momento de confronto da teoria com a prática, sendo que, deste embate, deveria haver a motivação para a reflexão em busca de novos conhecimentos, novos saberes e 
novos modos de agir - a práxis. Particularmente, também entendemos o estágio como elemento fundamental de conhecimento da prática escolar, sendo momento oportuno de produção de reflexões profundas sobre a profissão docente. Inclusive possibilitando o acesso a pormenores do cotidiano que não fazem parte do escopo da formação universitária. De fato, o estágio pode e deve, inclusive, ser um caminho de retroalimentação aos cursos de Pedagogia, ao possibilitar o acesso a essas particularidades da rotina escolar.

\section{O Ensino Fundamental de 09 Anos}

Eis a etapa de maior duração da Educação Básica, que compreende os estudantes de 06 a 14 anos (ora alguns com 05 ou 15). Aqui se notam importantes mudanças que acontecem nos alunos, que passam da infância para a adolescência; mudanças não somente físicas, mas emocionais, cognitivas, afetivas e sociais.

Do $1^{\circ}$ ao $5^{\circ}$ anos, os anos iniciais do ensino fundamental, o Professor Polivalente tem a importante função de alfabetizar. Neste período de cinco anos, torna-se responsável por todos os conteúdos condizentes com o currículo dos anos iniciais do Ensino Fundamental. Pelo menos é com tem sido feto o trabalho há algum tempo, inclusive estando expresso na Base Nacional Comum Curricular, a BNCC (BRASIL, 2018): "nos dois primeiros anos desse segmento, o processo de alfabetização deve ser o foco da ação pedagógica” (p. 63). Trata-se do período para apropriação do sistema de escrita alfabético, que acontece ao mesmo tempo em que se apropria de habilidades leitoras e de escrita. A esse respeito, nos explica Soares (2005, p. 24):

O termo alfabetização designa o ensino e o aprendizado de uma tecnologia de representação da linguagem humana, a escrita alfabético-ortográfica. $\mathrm{O}$ domínio dessa tecnologia envolve um conjunto de conhecimentos e procedimentos relacionados tanto ao funcionamento desse sistema de representação quanto às capacidades motoras e cognitivas para manipular os instrumentos e equipamentos de escrita.

Para essa tarefa é preciso que o Professor Polivalente tenha conhecimento sobre como o aluno aprende, como constrói o conhecimento. Embora isso esteja previsto nas diretrizes curriculares, alfabetizar é uma tarefa complexa que exige estudo e muita prática por parte daquele que vai promovê-la. Quando se está na escola em uma posição administrativa e/ou de coordenação pedagógica, por exemplo, percebe-se que muitos professores não possuem o chamado "perfil alfabetizador". Esses professores tendem a preferir a classes de $4^{\circ}$ e $5^{\circ}$ anos, que já prevê a leitura e a escrita autônomas dos alunos. Essa opção por este ou aquele ano 
cabe, quase sempre, ao professor; mas, essa opção pode sofrer interferências externas, por exemplo, no momento de sua escolha não ter mais aquele ano que prefere, o que o obriga a se encaminhar para outros anos. Dessa forma, mesmo sem a preferência pelo trabalho com alfabetização, essa atribuição faz parte do rol de tarefas de um Professor Polivalente. Por isso é importante a formação inicial focar nessa polivalência, sendo algo inerente ao cargo docente de quem é egresso da licenciatura em Pedagogia.

Cada ano letivo possui, no mínimo, 200 dias letivos durante os quais uma gama de assuntos são tratados em Língua Portuguesa, Matemática, História, Geografia e Ciências. Todos esses componentes curriculares possuem suas complexidades, suas especificidades. Em um dia de aula, o professor leciona cerca de duas ou três disciplinas, com conteúdos distintos, e isso pode gerar certo conflito aos professores, pois quando se está à frente de 30 alunos, não basta saber o conteúdo, mas conhecer meios que possibilitem ensinar distintos e diversos conteúdos curriculares a muitos e diferentes estudantes. Tarefa altamente complexa, que não pode ser tomada como algo trivial.

\section{A Gestão Escolar}

A Gestão Escolar compreende os cargos administrativos e pedagógicos de uma unidade escolar como: Diretor, Vice-Diretor, Coordenador Pedagógico, Orientador Educacional entre outros (ou outras nomenclaturas dadas pelas secretarias de educação). As Diretrizes Curriculares Nacionais são claras quanto às expectativas de quem ocupa um cargo de gestão, e a partir da BNC de Formação, especifica a carga horária mínima e o itinerário formativo de cada um. Devem zelar pela construção de uma cultura escolar proativa, capaz de assumir com autonomia resoluções e produzir os encaminhamentos necessários para as diversas problemáticas do cotidiano, além de produzir aprendizado a partir disto.

Planejamento, execução, coordenação e avaliação são terminologias amplas que condizem ao escopo de trabalho do Diretor, de seu Vice-Diretor e do Coordenador Pedagógico. É de responsabilidade do Diretor a condução administrativa da escola, que inclui prestar contas das verbas recebidas para as atividades escolares do ano vigente e subsequentes, bem como planejar em como melhor aplicar os recursos no ambiente da escola, tendo no seu cerne um modelo de gestão democrática, contando com o apoio dos seus Conselheiros (conselho formado por pais, professores e a comunidade escolar).

Também é importante mencionar o trabalho exercido pelo Coordenador Pedagógico, que também é uma função de Gestão. Este tem em seu escopo a responsabilidade de 
administrar a dimensão pedagógica de uma unidade escolar, as avaliações, além de atuar como um articulador entre todos os envolvidos de uma escola, sejam eles profissionais, familiares ou estudantes. Segundo expressam Placco e Almeida (2015), o Coordenador Pedagógico é articulador, formador e transformador, pois, além de ser uma metafórica ponte entre diferentes atores da comunidade escolar, é o responsável pela formação continuada em exercício do corpo docente, promovendo momentos de reflexão entre professores, para aprimoramento das práticas exercidas na escola.

\section{Professor Polivalente: em meio a tudo isso, quem sou?}

Discutir, porém, a questão da identidade dos sujeitos da educação, educadores e educandos, me parece que implica desde o começo de tal exercício, salientar que, no fundo, a identidade cultural, expressão cada vez mais usada por nós, não pode pretender exaurir a totalidade da significação do fenômeno cujo conceito é identidade [...] Conseguimos, ao longo dele uma longa história, deslocar da espécie o ponto de decisão de muito do que somos e do que fazemos para nós mesmos individualmente, mas, na engrenagem social sem a qual não seríamos também o que estamos sendo. No fundo, nem somos só o que herdamos nem apenas o que adquirimos, mas a relação dinâmica, processual do que herdamos e do que adquirimos (FREIRE, 1997, p. 63, grifo do autor).

Tratar sobre a identidade do Professor Polivalente é construir o significado para aquilo que durante anos adquirimos no processo da prática. Como citado por Freire (1997), somos a junção daquilo que herdamos e do que adquirimos, ou seja, em nossos estudos como alunos da Educação Básica, alunos da graduação e no âmbito escolar como professores, adquirimos conhecimento, vivências, e nos tornamos o que somos a partir de tudo isso, reorganizando nossos valores e atitudes conforme vamos modificando e sendo modificados pelos saberes e pelas experiências. Para Tardif e Lessard (2005, p. 271):

O trabalho docente é interagir com alunos que são todos diferentes uns dos outros e, ao mesmo tempo, atender a objetivos próprios de uma organização de massa, baseada em padrões gerais. Trabalhando com coletividades, o professor também age sobre indivíduos. Aí está um elemento essencial desse trabalho que é, ao mesmo tempo, uma tensão central deste ofício: lidar com coletividades atingindo os indivíduos que as compõem.

A escola, como local de conhecimentos e de culturas, também desenvolve identidade própria devido às inúmeras relações pessoais e subjetivas que a compõe. O professor que leciona em determinada unidade escolar passa a criar vínculos neste ambiente que atua, acrescentando detalhes identitários. A identidade docente está relacionada ao cotidiano e às experiências que o compõem como sujeito. Para Pimenta (2012, p. 19): 
A identidade não é mutável. Nem externo, que possa ser adquirido. Mas é um processo de construção do sujeito historicamente situado. A profissão de professor, como as demais, emerge em dado contexto e momentos históricos, como resposta a necessidades que estão postas pelas sociedades, adquirindo estatuto de legalidade.

Há um dinamismo na profissão professor, constantemente exposta às práticas sociais e interações. Essa jornada anual se reinicia com o processo de atribuição de novas salas, ao conhecer seus novos alunos, o que está alinhado respectivamente a novos desafios. Pimenta (2012) também aborda o significado do conceito de identidade, afirmando o seguinte:

Uma identidade profissional se constrói, pois, a partir da significação social da profissão; da revisão constante dos significados sociais da profissão; da revisão das tradições. Mas também da reafirmação de práticas consagradas culturalmente e que permanecem significativas. Práticas que resistem a inovações porque estão prenhes de saberes válidos às necessidades da realidade. Do confronto entre as teorias e as práticas, da análise sistemática das práticas à luz das teorias existentes, da construção de novas teorias. Constrói-se, também, pelo significado que cada professor, enquanto ator e autor, confere à atividade docente no seu cotidiano a partir de seus valores, de seu modo de situar-se no mundo, de sua história de vida, de suas representações, de seus saberes, de suas angústias e anseios, do sentido que tem em sua vida o ser professor (PIMENTA, 2012, p. 20).

Pimenta (2012) detalha o conceito de identidade docente, afirmando que a construímos a partir da prática, das relações sociais externas e internas, do modo como a sociedade enxerga esta profissão, da forma como os profissionais que ali estão enxergam seus professores e, a partir deste conjunto de relações, olhares e significados, ao longo do tempo, construímos a identidade docente. Imbernón (2009), ao tratar de identidade docente, explicita que nela existe um dinamismo em relação à forma de ver e transformar a realidade social e educativa. Logo, a identidade docente é construída paulatinamente, de forma dinâmica, levando em conta as intempéries que podem ocorrer tanto na graduação como na formação continuada em serviço ou no exercício da função escolar. A seguir, uma experiência vivida por um de nós como Professor Polivalente, na cidade de Itu, interior de São Paulo, alguns anos atrás.

\section{Uma professora alfabetizadora}

Trabalho em uma unidade de ensino de $1^{\circ}$ ao $5^{\circ}$ Ano, fundada em 1916. São mais de 100 anos de história, é uma das escolas municipais mais antigas. Quando comecei a trabalhar na prefeitura, em escolas distantes, pensava que um dia, quando tivesse a pontuação maior, eu 
iria trabalhar nesta escola. O prédio em que ela se situa é clássico, uma obra arquitetônica singular, que hoje está sendo restaurada para abrigar novamente a escola (há quase dez anos ela ocupa outro prédio, para que fosse feita a restauração neste que descrevo). Não precisei esperar por anos uma vaga nesta unidade, pois fui convidado a ser coordenador nela, e cá estou há nove anos. A breve descrição é para elucidar o que eu sinto ao conviver com as professoras que compõem o quadro desta escola. Não é fácil ter uma vaga disponível na atribuição, até porque as primeiras da lista sempre a escolhem. Nesta escola é possível conviver com professoras que estudaram ali, como alunas, e se tornaram professoras pelo Magistério, depois Pedagogas pela Universidade e permaneceram na mesma escola lecionando. Trago comigo, alguns sentimentos sobre o saber construído por elas, dificilmente compreendido pelos estudos teóricos, pois requer muita prática: o saber alfabetizador. Como coordenador, já estive em sala observando, entendi alguns processos, mas, essa professora, em especial, possui a expertise da alfabetização. Ela tem um jeito, uma forma, uma fala alfabetizadora. Vibra quando um aluno consegue juntar as letras e ler suas primeiras sílabas. Compartilha com os colegas essas pequenas vitórias. Recentemente, recebeu reconhecimento por ser uma das professoras mais antigas da Prefeitura, e lá se foram 37 anos de magistério! Lecionou para filhos que se tornaram pais de seus atuais alunos. O saber da alfabetização ela construiu no dia a dia. Quando a observo, é visto o amor que ela tem pelo que faz, a energia em se dedicar aos alunos, e, se preciso, até pegar na mão deles para que se construam as primeiras grafias. Existe um tom de voz, uma serenidade que, sem dúvida, auxilia no processo de alfabetizar. São anos de dedicação e construção de um aprendizado. Ela construiu uma identidade alfabetizadora (usando o conceito de forma livre) e, sempre faz questão de escolher os $1^{\circ}, 2^{\circ}$ e $3^{\circ}$ anos, pois prefere alfabetizar. O sentimento que não guardo para minha pessoa e sempre que posso coloco para reflexão com as professoras em nossas reuniões semanais, é que existem saberes que a Academia ignora pelo seu caráter empírico. O saber, por exemplo, da forma de alfabetizar dessa referida professora, não sistematizado nos livros, e que provavelmente se perderá quando deixar de lecionar

O relato traz, de forma simplificada, obviamente, o processo de construção da identidade docente na e pela prática. Os professores que estão na escola, no dia a dia, assumem posições identitárias, posições construídas no exercício de sua função. Aprenderam no ensino superior, no magistério, e permanecem em aprendizado no dia a dia da escola, em cada ano que leciona, com cada aluno que passa pelas suas aulas. Muitos docentes buscam compartilhar e ensinar seus colegas. Não é raro ter momentos de ensino entre professores, que indicam essa ou aquela atividade, ou que problematizam questões ou formas de ensinar, para 
que os alunos progridam. Esses momentos também fazem parte da construção da identidade docente.

Tardif e Lessard (2005) afirmam que as competências adquiridas pela socialização são de difíceis mensuração. "É por isso que nunca é suficiente descrever, mesmo que detalhadamente, tudo que se passa numa escola ou numa classe, para compreender a ordem das interações", afirmam (p. 170) e complementam: "é preciso também compreender as interpretações, significações e intenções dos parceiros da ação" (p. 170). Isso quer dizer que existe um conjunto de elementos para o entendimento do que é identidade e como ela é construída ao longo do tempo, pelas múltiplas vivências do cotidiano escolar.

E sobre a identidade de alfabetizar, do modo singular de operar este mecanismo, autores como Ferreiro (1986), Russo (2013), Morais (2012), Ferrero e Teberosky (1999) tratam de formatos de alfabetização, do que e do como alfabetizar, cada qual com seu método e linha de pensamento. Mas, existe uma prática alfabetizadora que não está nos livros, pois é empírica, vivida na prática como uma miscelânea dos métodos, ou mesmo ausência de métodos. Pimenta (2012) tem um nome para isso, são as práticas que "estão prenhes de saberes válidos às necessidades da realidade" (p. 20). São as metodologias e saberes construídos por professores nas salas de aula, reorganizados a partir dos métodos e das teorias, mas em contato vivo com as mais singulares identidades de cada estudante. O relato anterior sobre a professora alfabetizadora, no auge das suas quatro décadas de experiência, trata desse saber, do diálogo de identidade na teoria e como ela se constrói com os anos de exercício da função.

Há autores que, ao abordar identidade, trazem o conceito de ensino como vocação. Para Snyders e Lopez (2007) isso se define como uma forte motivação na qual uma pessoa repetidamente assume uma atitude intrinsecamente satisfatória. Se o Professor Polivalente se comporta como tal, com vocação em seu trabalho, e desse fator permanece otimista em suas tarefas, isso irá se refletir em sua prática, consequentemente demonstrando afeto, sentido e até amor no que faz.

Para Imbernón (2000), o desenvolvimento da profissão docente e sua identidade se desenvolvem na junção de muitos fatores da profissão, não sendo possível entende-la como pura vocação, pois tem relação com salários, mercado de trabalho, carreira, ambiente de trabalho etc. Nessa mesma direção, Tardif e Lessard (2005) anotam o seguinte:

[...] a escola possui algumas características organizacionais e sociais que influenciam o trabalho dos agentes escolares. Como lugar de trabalho, ela não é apenas um espaço físico, mas também um espaço social que define 
como o trabalho dos professores é repartido e realizado, como é planejado, supervisionado, remunerado e visto por outros. Esse lugar também é o produto de convenções sociais e históricas que se traduzem em rotinas organizacionais relativamente estáveis através do tempo. É um espaço sócioorganizacional no qual atuam diversos indivíduos ligados entre si por vários tipos de relações mais ou menos formalizadas, abrigando tensões, negociações, colaborações, conflitos e reajustamentos circunstanciais ou profundo de suas relações (TARDIF; LESSARD, 2005, p. 55).

O espaço da escola é elemento constitutivo da identidade do professor, pois, neste local, uma gama de relações e de tensões faz com que cada um se torne elemento essencial na construção do outro. Assim, a construção da identidade é também influenciada e/ou motivada por todos que se relacionam no espaço escolar: professores, alunos, funcionários e demais integrantes da comunidade escolar. Trata-se de um processo em constante desenvolvimento, muito bem capturado pelas palavras de Rubem Alves (1982):

Eu diria que os educadores são como velhas árvores. Possuem uma face, um nome, uma estória a ser contada. Habitam um mundo em que o vale é a relação que os ligam aos alunos, sendo que cada aluno é uma entidade "sui generis", portador de um nome, também de uma estória, sofrendo tristezas e alimentando esperanças. E a educação é algo pra acontecer neste espaço invisível e denso, que se estabelece a dois. Espaço Artesanal (ALVES, 1982, p. 22).

Ensinar é artesanal, é algo único, feito com as mãos. O Professor Polivalente vai compreendendo essa artesania conforme percebe sua própria evolução desde os anos de graduação e busca aprimorar sua docência por meio de processos de formação continuada. $\mathrm{O}$ entendimento das mais variadas formas de ensinar contribui com a sociedade, com o ensino de meninos e meninas presente nas escolas. Ser professor é, então, realizar cotidianamente artesanias que acontecem, como vimos com Alves (1982), no encontro entre educador e educando, reciprocamente transformando-os. Isso, mais uma vez, nos remete a Paulo Freire (1996) e seu importante axioma: quem ensina aprende ao ensinar e quem aprende ensina ao aprender.

\section{Considerações finais}

Tenho certeza de que um dos saberes indispensáveis à luta das professoras e professores é o saber que devem forjar neles, que devemos forjar em nós próprios, da dignidade e da importância de nossa tarefa (FREIRE, 1997, p. $32)$.

A tarefa de lecionar, de estar em uma escola, de lutar pela educação de meninos e meninas é altamente complexa. Muitas tarefas escolares se atribuem ao licenciado em 
Pedagogia, então, começamos o artigo buscando especificar as diversas atribuições que um Professor Polivalente pode assumir após a conclusão de sua graduação: lecionar na Educação Infantil, Ensino Fundamental de $1^{\circ}$ ao $5^{\circ}$ Ano, no Ensino Médio na modalidade Normal, no Ensino de Jovens e Adultos (EJA) e demais instituições com práticas escolares ou não escolares, inclusive lecionar no sistema prisional. Ainda, o licenciado em Pedagogia pode se tornar gestor de uma Unidade de Ensino, diretor, vice-diretor e coordenador. Somado a todas estas funções, está apto a exercer o ensino para pessoas com deficiência e, principalmente, por construir planos pedagógicos e de ensino para as categorias indicadas.

Trouxemos um breve panorama sobre a Educação Infantil, contudo, apresentamos detalhes e vivências da prática escolar, incluindo correções de rota e outras particularidades que somente se descortinam com a experiência. Evidenciamos, então, a importância do estágio supervisionado na formação do Professor Polivalente, pois é o momento em que se pode aprender pormenores do exercício docente com colegas mais experientes, portanto, conhecedores de diversas situações difíceis de serem previstas nas disciplinas dos cursos de licenciatura em Pedagogia.

Também discutimos sobre o Ensino Fundamental de 09 anos e a função do Professor Polivalente como alfabetizador, trazendo uma reflexão sobre a tarefa do processo de alfabetização. Abordamos a ideia de que existem Professores Polivalentes mais interessados em aturem como alfabetizadores, e que se constituem desta forma com habilidade e maestria para tal tarefa. Esses professores compreendem os processos de aprendizagem do aluno e sabem intervir para que aquele que começa a conhecer as letras se torne alguém que saiba ler e escrever, portanto, se comunicando e se inserindo no mundo pela palavra escrita. Freire (1981) trata sobre o letramento e como se dá o processo de leitura: o aluno atribui um significado da leitura de seu mundo para a leitura convencional. Entende-se então o significado das palavras, o que possibilita a busca pelo seu contexto. Nos anos iniciais, o Professor Polivalente atua a frente de todas as disciplinas que compõem o currículo dessa etapa.

Discutimos, então, a Gestão Escolar que compreende algumas funções distintas: direção, vice-direção e coordenação. Para estas funções, o Professor Polivalente precisa se inteirar sobre diversas outras atividades além da sala de aula. Seu pensamento já não é mais exclusivamente pedagógico, precisando atuar na gestão, tomando decisões a respeito de toda comunidade escolar. A coordenação pedagógica é o elo entre os diversos envolvidos da escola, como também é responsável pela formação continuada em serviço. Domingues (2014) indica que para esta função, de Coordenador, o curso de Pedagogia é essencial, pois prepara 
para as diversas situações didáticas e metodológicas que podem acontecer em uma rotina escolar. Para Libâneo (2003), o entendimento sobre gestor, atribuído pelas Diretrizes, é a função que canaliza o trabalho em conjunto das pessoas para que se concretizem os objetivos educacionais.

Todas as atribuições do Professor Polivalente, gestão ou docência, o colocam à frente da inclusão, do respeito e valor às diferenças. Esses temas precisam sempre ser articulados com o contexto escolar e suas diversidades, seja na sala de aula, com 10, 20 ou mesmo 35 estudantes, seja numa escola com mil estudantes ou mais. O Professor precisa ser um agente promotor da inclusão, buscando atender às necessidades de aprendizagem de todo alunado.

O espaço de atuação do Professor Polivalente é, portanto, amplo. As interações da prática escolar podem ser elementos constitutivos de identidade desse profissional. Ao final, este artigo não encerra no sentido de aconselhar, pois nem teríamos as condições necessárias para isso. Apenas produz um possível panorama sobre as atribuições do Professor Polivalente, refletindo sobre a formação inicial desse profissional. O campo é complexo, desafiador, mas potencialmente transformador. Por isso, vale a pena.

\section{REFERÊNCIAS}

ALVES, R. O preparo do educador. In: BRANDÃO, C. R. (Org). Educador: vida e morte. 2. ed. Rio de Janeiro: Graal, 1982. p. 22-30.

BRASIL. Ministério da Educação. Conselho Nacional de Educação. Diretrizes Curriculares Nacionais para o Curso de Pedagogia. Brasília, DF: 2005.

BRASIL. Ministério da Educação. Conselho Nacional de Educação. Reexame do parecer CNE/CP no 5/2005, Diretrizes Curriculares Nacionais para o Curso de Pedagogia. Brasília, DF: 2006.

BRASIL. Ministério da Educação. Conselho Nacional de Educação. Conselho Pleno. Resolução CNE/CP n2/2015. Define as diretrizes curriculares nacionais para a formação inicial em nível superior (cursos de licenciatura, cursos de formação pedagógica para graduados e cursos de segunda licenciatura) e para formação continuada. Brasília, DF: MEC, 2015. Disponível em: http://portal.mec.gov.br/docman/agosto-2017-pdf/70431-res-cne-cp002-03072015-pdf/file. Acesso em: 15 nov. 2018.

BRASIL. Base Nacional Comum Curricular. Brasília: MEC, 2017. Disponível em: http://basenacionalcomum.mec.gov.br/images/BNC C_20dez_site.pdf. Acesso em: 22 dez. 2017.

BRASIL. Ministério da Educação. Conselho Nacional de Educação. Resolução CNE/CP n²/2019. Define as Diretrizes Curriculares Nacionais para a Formação Inicial de Professores 
para a Educação Básica e institui a Base Nacional Comum para a Formação Inicial de Professores da Educação Básica (BNC-Formação). Brasília, DF: 2019.

CANDAU, V. M. (Org.). Didática: questões contemporâneas. Rio de Janeiro: Forma \& Ação, 2008.

CONTRERAS, J. D. Relatos de experiencia en busca de un saber pedagógico. Revista Brasileira de Pesquisa (Auto) Biográfica, Salvador, v. 1, n. 1, p. 14-30, jan./abr. 2016.

FERREIRO, E.; TEBEROSKY, A. A psicogênese da língua escrita. Porto Alegre: Artmed, 1999.

FERREIRO, E. Reflexões sobre a alfabetização. São Paulo: Cortez, 1986.

FORTUNATO, I. Tornar-se professor: Reflexões iniciais sobre um percurso paradoxal. South American Journal of Basic Education, Technical and Technological, v. 4, n. 1, p. 4-9, 2017.

FREIRE, P. Professora sim, tia não: cartas a quem ousa ensinar. São Paulo: Olho d'água, 1997.

FREIRE, P. Pedagogia da autonomia: saberes necessários à prática docente. São Paulo: Paz e Terra, 1996.

FREIRE, P. Prefácio. In: SNYDERS, G. Alunos felizes: reflexão sobre a alegria na escola a partir de textos literários. Rio de Janeiro: Paz e Terra, 1993.

FREIRE, P. Educação: o sonho possível. In: BRANDÃO, C. R. (Org.). Educador: vida e morte. 2. Ed. Rio de Janeiro: Graal, 1982, p. 89-101.

IMBERNÓN, F. Formação docente e profissional: formar-se para a mudança e a incerteza. São Paulo: Cortez, 2000.

IMBERNÓN, F. Formação permanente do professorado: novas tendências. São Paulo: Cortez, 2009.

MORAIS, A. G. Sistema de escrita alfabética. São Paulo: Melhoramentos, 2012.

PLACCO, V. M. N. S.; ALMEIDA, L. R. (Org). O coordenador pedagógico no espaço escolar: articulador, formador e transformador. São Paulo: Edições Loyola, 2015.

PIMENTA, S. G. (Org.). Pedagogia e pedagogo: caminhos e perspectivas. São Paulo: Cortez, 2011.

PIMENTA, S. G. (Org.). Saberes pedagógicos e atividade docente. São Paulo: Cortez, 2012.

RUSSO, M. F. Alfabetização. São Paulo: Saraiva, 2013. 
SNYDER, C. R.; LOPEZ, S. J. Psicologia positiva: uma abordagem científica e prática das qualidades humanas. Porto Alegre: Artmed, 2007.

SNYDERS, G. Alunos felizes: reflexão sobre a alegria na escola a partir de textos literários. São Paulo: Paz e Terra, 1993.

SOARES, M. B. Alfabetização e letramento: caderno do professor. Belo Horizonte: Ceale, 2005.

TARDIF, M.; LESSARD, C. O trabalho docente: elementos para uma teoria da docência como profissão de interações humanas. Petrópolis: Vozes, 2005.

VACILOTTO, E. Professor polivalente: reflexões para um caminho de incertezas.

Orientador: Ivan Fortunato. 2020. 109 f. Dissertação (Mestrado em Educação) - Universidade Federal de São Carlos, Sorocaba, 2020. 


\section{Como referenciar este artigo}

VACILOTTO, E.; FORTUNATO, I. Pedagogia e o professor polivalente: um campo complexo de atuação profissional. Doxa: Rev. Bras. Psico. e Educ., Araraquara, v. 22, n. 2, p. 364-380, jul./dez. 2020. e-ISSN: 2594-8385. DOI: https://doi.org/10.30715/doxa.v22i2.14106

Submetido em: $30 / 03 / 2020$

Aprovado em: 20/05/2020

Publicado em: 31/08/2020 